metabolite) and pulmonary morbidities in early neonatal period in premature infants.

Method This study was conducted in Hacettepe University Children's Hospital Neonatalogy Unit. Cord blood samples were obtained at birth from premature infants (gestational age $<37 \mathrm{wk}$ ) and theophylline levels were measured. Cord blood theophylline levels of infants with and without respiratory morbidities were compared.

Results A total of 60 infants were enrolled in the study. Early respiratory morbidities developed in 37 infants (Group 1, 61.6\%) while no respiratory morbidities were observed in 23 infants (Group 2, $38.3 \%)$. Although mean cord blood theophylline levels were lower in Group $1(0.21 \pm 0.18 \mu \mathrm{g} / \mathrm{ml})$ than Group $2(0.33 \pm 0.29 \mu \mathrm{g} / \mathrm{ml})$, this difference was not statistically significant ( $\mathrm{p}=0.156)$.

Conclusion Preterm infants with and without respiratory morbidities have similar cord blood teophylline levels. Prenatal exposure to theopylline does not seem to affect respiratory status in the early neonatal period. However cord blood theophylline levels were much lower than therapeutic serum levels in neonates. The effects of prenatal caffeine on neonatal respiratory status should be investigated in animal models.

\section{EPIDEMIOLOGICAL AND CHRONOLOGICAL PROFILE OF THE LOW BIRTH WEIGHT IN THE REGION OF MONASTIR (TUNISIA) BETWEEN 1995 AND 2008}

doi:10.1136/archdischild-2012-302724.1296

S El Mhamdi, I Bouanene, K Ben Salem, MS Soltani. University of Monastir, Monastir, Tunisia

In Tunisia, despite the activities of national programs of maternal and child health, low birth weight (LBW) remains common. The aim of this study is to draw up the epidemiological profile of the LBW in the region of Monastir and to study the chronological trends of the associated factors during a period of 14 years (1995-2008). We conducted a population study which interest 97.630 live births (from 26 to 43 weeks) in the public maternities of the region of Monastir. The mean's age of pregnant women was $28.7 \pm 5.5$ years. Among them $14.2 \%$ were aged 35 and older and $40 \%$ were primipara. Newborns were in term in $94.7 \%$ of cases. Maternal age, prenatal care, twin pregnancies and fetal complications were the factors independently associated with the occurrence of LBW in term newborns. However, only prenatal care and twin pregnancies were independently associated to LBW in preterm newborns. During the fourteenth years of the study the parturient mean age and the frequency of preterm birth increased significantly $(\mathrm{P}<0.001)$ while the frequency of multiparty decreased significantly $(\mathrm{P}<0.001)$. We found that the risk factors of LBW (advanced age, multiparty, etc.) are still common in our country and require targeted interventions.

\section{A RANDOMIZED CLINICAL TRIAL OF THE USE OF ORAL GLUCOSE FOR PAIN RELIEF DURING RETINOPATHY OF PREMATURITY EXAMINATION (ROP)}

doi:10.1136/archdischild-2012-302724.1297

RS Procianoy, M Costa, G Eckert, B Borges Fortes, J Fortes Filho, RC Silveira. Universidade Federal do Rio Grande do Sul and Hospital de Clinicas de Porto Alegre, Porto Alegre, Brazil

Background Ophthalmologic examination for ROP is a painful procedure. Pharmacological and non-pharmacological interventions have been proposed in order to reduce pain during eye examination.

Purpose To evaluate the use of oral $25 \%$ glucose solution to relief pain during ophthalmologic examinations for ROP.

Methods A masked randomized clinical trial with the use of $1 \mathrm{ml}$ of oral $25 \%$ glucose solution once 2 minutes before the first ophthalmologic examination was carried out from March 2008 to April 2010 comparing with a control group that did not receive oral glucose solution. Pain was evaluated by Neonatal Infant Pain Scale (NIPS) immediately before and immediately after the ophthalmologic examination in both groups.

Results 124 patients who were examined for the first time for ROP were included (70 in intervention and 54 in control groups). Prior to examination, mean NIPS scores were $0.8 \pm 0.8$ and $1.2 \pm 1.2(\mathrm{P}=0.100)$ in newborns of intervention and control groups respectively, and

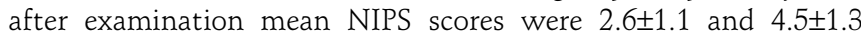
$(\mathrm{P}<0.001)$ in intervention and control groups respectively. The number of patients with pain prior the eye examination was one $(1.4 \%)$ and $2(3.7 \%)$ in intervention and control groups ( $\mathrm{P}=0.580)$ respectively. After eye examination 11 patients with pain (NIPS $\geq 4$ ) in intervention group $(15.7 \%)$ and 37 patients with pain $(68.5 \%)$ in control group $(\mathrm{P}<0.001)$.

Conclusions One $\mathrm{ml}$ of oral $25 \%$ glucose solution given 2 minutes before the ophthalmologic examination for ROP is an effective measure for pain relief. (clinicaltrials.gov. NCT00648687).

\section{PREDICTIVE VALUE OF UMBILICAL CORD BLOOD BILIRUBIN LEVEL FOR SUBSEOUENT HYPERBILIRUBINEMIA IN ABO INCOMPATIBILITY}

doi:10.1136/archdischild-2012-302724.1298

'D Bhat, ${ }^{2} \mathrm{M}$ Purohit. 'Dayanand Medical College, Ludhiana; ${ }^{2}$ S.P.Medical College, Bikaner, India

Objectives To establish a correlation between umbilical cord blood bilirubin levels and the development of subsequent hyperbilirubinemia in healthy term newborn $\mathrm{ABO}$ incompatible infants of blood group "O" mothers.

Subject \& methods One hundred consecutive healthy full term offsprings of $\mathrm{ABO}$ incompatible pregnancies and 30 controls resulting from $\mathrm{O}-\mathrm{O}$ pregnancies were studied. Blood group and serm bilirubin estimations were carried out on cord blood and bilirubin estimation was further done at 36 hours of life.

Results Out of 100 cases in study group 33(33\%) developed hyperbilirubinemia whereas only one (3.3\%) out of 30 cases in control group developed hyperbilirubinemia. Majority of cases with hyperbilirubinemia i.e. $20(60.6 \%)$ out of 33 cases, had cord bilirubin values between 2.5 to $2.99 \mathrm{mg} / \mathrm{dl}$. Mean cord bilirubin values were significantly higher $(2.27 \pm \mathrm{U} 0.76)$ in study group as compared to compared to control group (1.55 \pm 0.33$)$.

Conclusion It is concluded that in $\mathrm{ABO}$ incompatibility the cord bilirubin value $\geq 2.5 \mathrm{mg} / \mathrm{dl}$ can serve as a useful cutoff limit for the later development of hyperbilirubinemia.

\section{ARE WE UNDERTREATING HYPERBILIRUBINEMIA IN PRETERM INFANTS?}

doi:10.1136/archdischild-2012-302724.1299

A Kage. Paediatrics, Leicester Royal Infirmary, Leicester, UK

Aim To compare serum bilirubin level for exchange transfusion in pre-term infants (<32 weeks) against standard guidelines.

Methodology Retrospective audit. Preterm infants ( $<32$ weeks) and Birth weight $<1500$ gms included. Data collected through Clinical Work Station. Bilirubin levels plotted on the charts used on our neonatal unit and compared against standard charts. (from Robertson's textbook of Neonatology).

Results No infant received exchange transfusion. When the levels were plotted on standard guideline charts, there were 8 infants who should have received exchange transfusion based on birth weight and 16 infants who should have received exchange transfusion based on gestation. 
Recommendations Consensus on bilirubin chart to be used.

National survey to find out the number of exchange transfusions done in preterm infants.

\section{FETAL ANALGESIA AND BRAIN DAMAGE}

doi:10.1136/archdischild-2012-302724.1300

C Bellieni, G Buonocore. Pediatrics and Obstetrics, University of Siena, Siena, Italy

Aim Fetal surgery is increasingly performed in many centers. Nevertheless, in most cases, analgesic treatment is still absent with the risk of brain damage in the newborn, due to the sudden rise in blood pressur and intracranial pressure due to pain. We performed a review on the present state of direct fetal analgesia, to show the importance to prevent pain and consequently newborns' brain damage in these cases.

Methods We performed a pubmed search to retrieve the research papers that reported studies of fetal surgery in the last 10 years, and in which a careful description of the type of analgesic treatment is reported.

Results We retrieved 38 papers, 3 of which did not sensibly hurt the fetus, being performed on fetal annexes, and 2 performed in the first trimester, when fetal pain is negligible. Of the 33 remaining papers, only 14 were performed using a direct fetal analgesia. No drawbacks were reported.

Conclusion Fetal direct analgesia though safe, is still performed only in less than half of cases. An implementation of its use is needed, to prevent brain damages in the newborns.

\section{EFFECT OF MYDRIATIC EYE DROPS ON CEREBRAL AND MESENTERIC TISSUE OXYGENATION IN VERY LOW BIRTH WEIGHT INFANTS; PRELIMINARY REPORT}

doi:10.1136/archdischild-2012-302724.1301

${ }^{1} \mathrm{H}$ Tatar Aksoy, ${ }^{1} \mathrm{SS}$ Oguz, ${ }^{2} \mathrm{Z}$ Özen Tunay, ${ }^{2} \mathrm{R}$ Yıldız, ${ }^{1} \mathrm{HG}$ Kanmaz, ${ }^{3} \mathrm{U}$ Dilmen. ${ }^{1} \mathrm{NICU}$, Zekai Tahir Burak Maternity and Teaching Hospital, Department of Neonatology; ${ }^{2}$ NICU, Zekai Tahir Burak Maternity and Teaching Hospital; '3Zekai Tahir Burak Maternity and Teaching Hospital/YIldırım Beyazıt University Department of Pediatrics, Ankara, Turkey

Preterm infants weighing less than $1500 \mathrm{~g}$ routinely undergo a series of eye examinations to screen for retinopathy of prematurity (ROP). Mydriatic eye drops used for pupil dilatation while these examinations may be absorbed by nasopharyngeal mucosa and gastrointestinal system that may cause neurological and gastrointestinal side effects rarely. We aimed to evaluate the effect of mydriatic eye drops on cerebral and mesenteric tissue oxygenation by near infrared spectroscopy (NIRS), in very low birth weight (VLBW) infants. Eleven preterm infants with a gestational age of $<32$ weeks and/or birth weight $<1500$ gr were included the study. Infants with intracranial hemorrhage (>grade II), PDA, major congenital anomalies, major heart disease, infection, anemia, thyroid disease, acidosis, history of perinatal asphyxia and surgery, not feeding orally, were excluded the study. Cerebral and mesenteric tissue oxygenation were measured by NIRS probes that located forehead and umbilical region before and after the mydriatic eye drops. Eleven ( 6 female, 5 male) infants were included the study. The median gestational age, birth weight, postnatal age and body weight during examination were 29 weeks, 1190g, 39 days and $1700 \mathrm{~g}$, respectively. Before the mydriatic eye drops mean cerebral and mesenteric $\mathrm{rSO}_{2}$ were $63.0 \pm 7.6$ and $54.9 \pm 10.1$, respectively. After the eye drops mean cerebral and mesenteric $\mathrm{SO}_{2}$ were $60.0 \pm 10$ and $51.7 \pm 9.9$, respectively. Although the slightly decrease in oxygenation after mydriatic eye drops there were no statistically significant differences $(p=0.6$ and $p=0.1)$. We believe that this difference may reach statistically significant levels in large study population.

\section{EPIDEMIOLOGY OF LATE PRETERM INFANTS (LPI): SAUDI TERTIARY CARE FACILITIES EXPERIENCE}

doi:10.1136/archdischild-2012-302724.1302

${ }^{1}$ A Mersal, 'A Almahbosh, ${ }^{2} \mathrm{~B}$ Binsadeqe. 'Pediatrics; '2Research Center, King Faisal Specialist Hospital \& Research Centre, Jeddah, Saudi Arabia

Introduction and Background Late preterm infants (LPI) are born at a gestational age between 34 weeks and 36 weeks and 6 days. They have higher morbidity and mortality than term infants due to their relative physiologic and metabolic immaturity.

Method Infants born between July 2008 and July 2010 are identified using NICU and Labor and delivery registry of King Faisal Specialist Hospital-Jeddah. The deliveries are around 1100 births per year. The pertinent data of all mothers and neonates delivered at KFSH\&RC-J abstracted from medical records.

Results 230 infants' enrolled; incidence rate of LPI in the year 2008 was $6.7 \%, 2009$ was $5.7 \%$ and $12.07 \%$ in 2012, 101 female and 128 male, 167 (72.6) had no maternal risk factors, artificial reproductive technology $55 / 230(23 \%)$, maternal hypertension is $5 / 230(2.2 \%)$. PROM is $3 / 230$ (1.3\%), no chorioamnionities or diabetes mellitus.

Cesarean sections $121 / 202(59 \%)$ in LPI, vs $200 / 392$ (51\%) in full term babies ventous delivery $2 / 202(1 \%)$ vs $7 / 392(1.8 \%)$.

Singleton vs. twin or triplet $59.7 \%$ vs. $28.7 \%$ or $11.6 \%$; the gravida the maternal age and gravida showed no difference; morbidity in LPI, respiratory distress syndrome 92/230 (40\%) hyperbilirubineamia required treatment $13 / 230$ (5.7\%), apnea $11 / 230$ (4.8\%), sepsis $21 / 230(9.5 \%)$, feeding problems $23 / 230(10 \%)$, hospital readmission $8 / 230$ (3.5\%). Admission to NICU was $116 / 229$ (50\%).

Conclusion Our result is very comparable with previous other studies, however the mortality rate in our series is negligible, perhaps related to our aggressive management and early admission to NICU for 48 hours observation.

\section{EVOLUTION OF NEONATAL MORTALITY IN THE NEONATAL DEPARTMENT - IN KOUBA HOSPITAL - ALGIERS}

doi:10.1136/archdischild-2012-302724.1303

S Alhallak, A Elhasane. Kouba Hospital, Algiers, Algeria

Introduction Neonatal deaths account for a large proportion of child deaths.mortality during neonatal period (2/3-3/4 our countrie)considered a good indicator of both maternal and newborn health and care.

Perinatal mortality:defined as nombre of stillbirths and deaths in the first weekof lif per 1000 births.

Objective To study evolutionof the rate of perinatal mortality, and to analyze the causes of this mortality.

Aims and methods: Data sources:

Registery of delivery room and registery of neonatal department.

Descriptive retrospective study on file of the newborn hospitalized in the department of neonatology during 11 years $(1 / 1 / 2001$ to31/12 2011).

In (2004-2005): adaptation of the infrastucture, equipment by materiels, recruitment, stabitity of the medical personnel.

Results In 11years 77099 births were recorded, among them 1569 stillbirths, a rate of global mortinatality of $20.35 \% 0$ in 2001 to $18 \% 0$ in 2006 to $15.2 \% 0$ in 2011 , the early neonatal mortalitywas $20.2 \% 0$ in 2001 to $13.6 \% 0$ in 2006 to $10.25 \% 0$ in 2011 . The perinatal mortality diminished from $50.6 \% 0$ in 2001 to $30.7 \% 0$ in 2006 to $25.3 \% 0$ in 2011.

The intra-hospital mortality lowered of $50 \%$, from $6.6 \%$ in 2001 to 3.48 in 2011 . She remained stable since 2007.

The causes of mortinatality by gravidic toxemia and its complications. The neonatal causes of deaths are dominated by exreme prematurity, DRS, asphyxia. The causes are often multiple and been interlinked. 